\section{UJMM

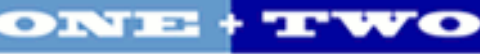

Volume 11 | 2021 Spring 2021

\section{Undergraduate Journal of Mathematical} Modeling: One + Two

2021

\title{
Area of Irregular Shaped Roof
}

Omar Alkhawaldeh

University of South Florida, alkhawaldeh@usf.edu

Advisors:

Arcadii Grinshpan, Mathematics and Statistics

Rasha Abu Olaim, CEO of Istaqim Design Company, Jordan

Problem Suggested By: Rasha Abu Olaim

Field of Study for Problem Suggester: CEO of Istaqim Design Company, Jordan

Follow this and additional works at: https://digitalcommons.usf.edu/ujmm

Part of the Mathematics Commons

UJMM is an open access journal, free to authors and readers, and relies on your support:

Donate Now

\section{Recommended Citation}

Alkhawaldeh, Omar (2021) "Area of Irregular Shaped Roof," Undergraduate Journal of Mathematical Modeling: One + Two: Vol. 11: Iss. 2, Article 3.

DOI: https://doi.org/10.5038/2326-3652.11.2.4931

Available at: https://digitalcommons.usf.edu/ujmm/vol11/iss2/3 


\section{Area of Irregular Shaped Roof}

Abstract

This project makes use of calculus, specifically integration, to find the exact area of a roof garden to minimize the cost of material used in flooring it. Since the roof is of irregular shape, it is divided into four sections, the integral of each section is taken, and a relationship between the integrals is generated.

Positive results are found, and the data reveal that the area of the grass floor is $175.3 \mathrm{~m}^{2}$ while the area of the wooden floor is $23.4 \mathrm{~m}^{2}$ with the total price being 2472 US dollars.

\section{Keywords}

irregular shape, area, integration, cost of material

\section{Creative Commons License}

\section{c) (i) $\Theta(\theta$}

This work is licensed under a Creative Commons Attribution-Noncommercial-Share Alike 4.0 License. 


\section{PROBLEM STATEMENT}

Find the exact area of the rooftop demonstrated by the floor plan below (Figure 1) for the purpose of determining the accurate amounts and costs of wood and artificial grass needed to floor it.

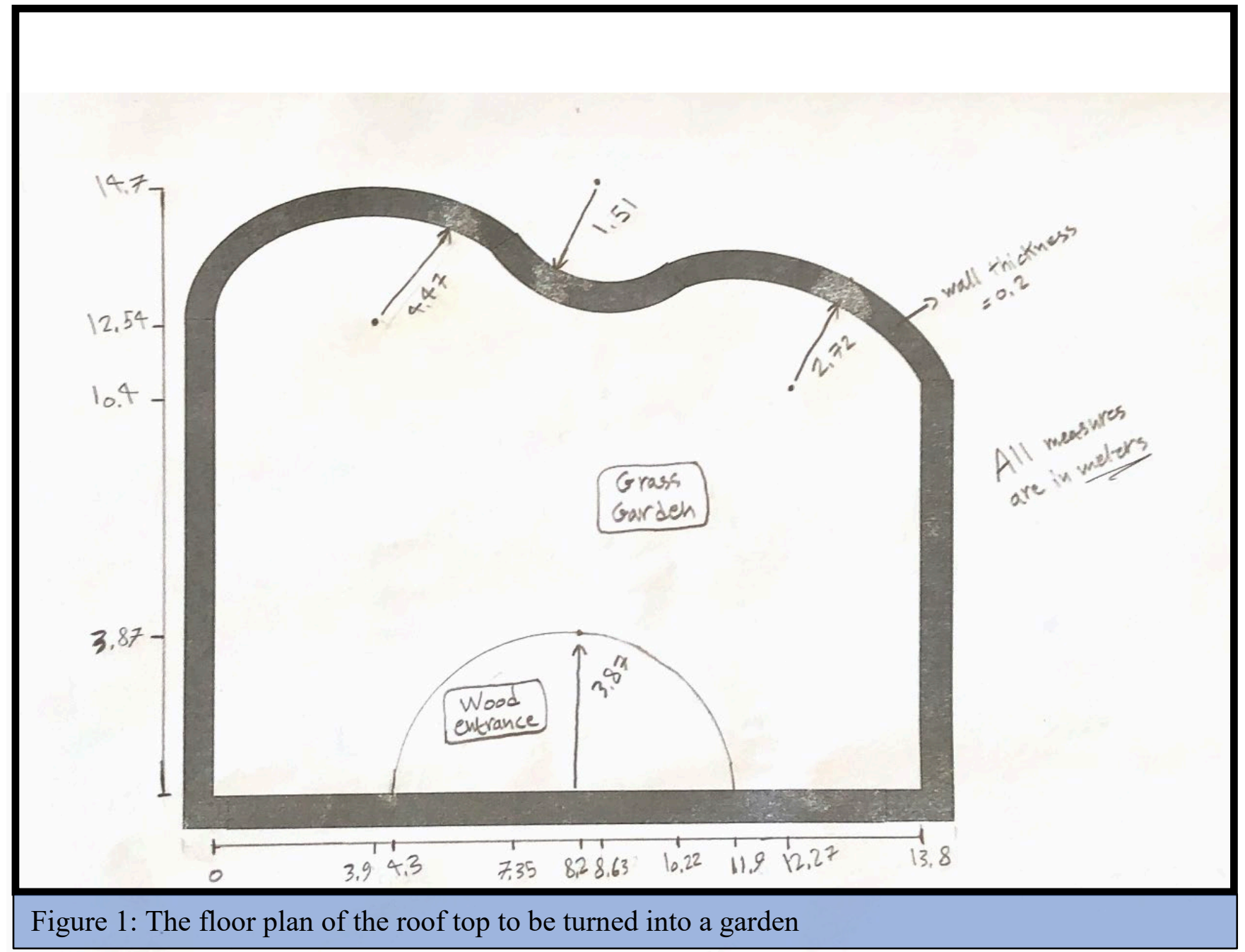




\section{MOTIVATION}

With all the trouble that COVID-19 has brought, going out to restaurants and parks became less wanted by people. Staying at home and quarantining became the solution. While staying at home, people tend to explore their houses and make them a comfortable place to stay. After noticing the empty spaces in their house, many people decide to contact house architects to help them out. One example of a famous design is a roof garden, where kids and pets can play without the fear of contacting unknown people (see Figure 3). Rooftops tend to have irregular shapes in a great number of houses which is a problem for architects because they are being forced to buy excess expensive material to floor them correctly. Some help from an engineer can reduce the cost on the architects and increase their profit. The exact area of an irregular roof can be calculated using integration in order to buy the correct amount of material needed.

\section{MATHEMATICAL DESCRIPTION AND SOLUTION APPROACH}

The area of the roof is determined by dividing it into 4 sections associated with four functions: $f_{1}(x), f_{2}(x), f_{3}(x)$, and $f_{4}(x)$ (see Figure 2). The first three sections present the area which will be floored with artificial grass and the fourth area presents the entrance which will be floored with wood. 


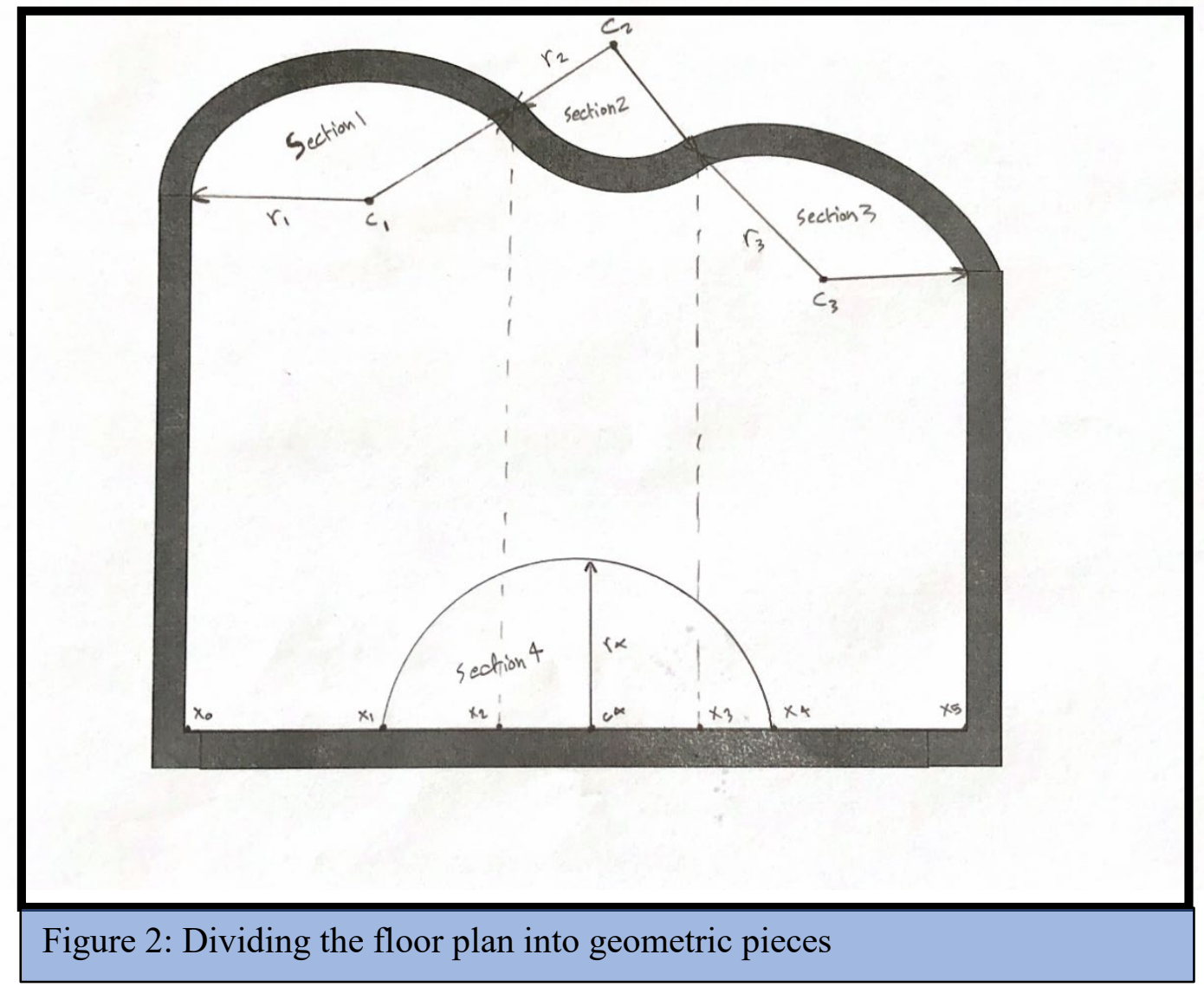

The floor plan shows that the upper border is curve while the lower border is a straight line. The concept of finding area between lines in Calculus is called the area between two curves. Here is its equation:

$$
\text { Area }=\int_{a}^{b}[f(x)-g(x)] d x, a \leq x \leq b
$$

where $f(x)$ is the function of upper curve while $g(x)$ is function of the lower curve. To account for the left and right borders, the integral is bounded between $a$ and $b$, two points on the curve. Since the second curve on the bottom is a straight line, $\mathrm{g}(x)=0$ in all the considered cases. 
To find the area of the first three sections, the sections' functions are plugged in equation (1) as follows:

$$
\text { Area (artificial grass) }=\int_{x_{0}}^{x_{2}} f_{1}(x) d x+\int_{x_{2}}^{x_{3}} f_{2}(x) d x+\int_{x_{3}}^{x_{5}} f_{3}(x) d x-\int_{x_{1}}^{x_{4}} f_{4}(x) d x
$$

The first three sections' functions: $f_{1}(x), f_{2}(x), f_{3}(x)$ are each put in an integral that is bounded by their limits on the xy-plane and summed together. Function $f_{4}(x)$ is also put in an integral but it is subtracted from the sum since it will be floored with wood instead.

After defining the relationship between functions and their areas, we figure out the equations that are presented by the functions. Since the shapes of the sections are rectangular ones with semi-circular ends, the equation of a circle of radius $r$ centered at $(h, k)$ is used:

$$
r^{2}=(x-h)^{2}+(y-k)^{2}
$$

Rearranging equation (3) in terms of y and restricting it to a semi-circle would result in:

$$
y=k \pm \sqrt{r^{2}-(x-h)^{2}}
$$

The plus minus sign refers to either the upper semi-circle or the lower semi-circle. In sections 1 , 3 , and 4, it is an upper semi-circle so it is a positive sign, while in section 2 it is a lower semicircle so it is a negative sign.

Each function $f_{n}(x)(n=1,2,3,4)$ can be defined by equation (4) and has three parameters $(h, k, r)$. Integration of these functions is based on a sin substitution. The values of the four circle centers $c_{1}, c_{2}, c_{3}, c_{4}$ (see Table 1) and the radii $r_{1}, r_{2}, r_{3}, r_{4}$ (see Table 2) are found 
by combining the measures in Figure 1 with the geometric pieces of Figure 2. Since the center of circle 2 is outside the roof, the value of $r_{2}$ is determined by adding the thickness of the wall, $0.2 \mathrm{~m}$ (see Figure 1).

Plugging in y for $f_{1}(x)$ in equation (2) and plugging in the corresponding values we have:

$$
\operatorname{Area}_{1}=\int_{x_{0}}^{x_{2}}\left[k+\sqrt{r^{2}-(x-h)^{2}}\right] d x
$$

Integrating equation (5) we obtain:

$$
\operatorname{Area}_{1}=\left.k x\right|_{x_{0}} ^{x_{2}}+\left.\frac{r^{2}}{2}\left[\arcsin \left(\frac{(x-h)}{r}\right)+\frac{\sin \left(2 \arcsin \left(\frac{(x-h)}{r}\right)\right)}{2}\right]\right|_{x_{0}} ^{x_{2}}
$$

Plugging in the corresponding values results in:

$$
\text { Area }_{1} \approx 120.749 \mathrm{~m}^{2}
$$

Then we use y for $f_{2}(x)$ :

$$
\operatorname{Area}_{2}=\int_{x_{2}}^{x_{3}}\left[k-\sqrt{r^{2}-(x-h)^{2}}\right] d x
$$

Integrating equation (6) we obtain: 
$\operatorname{Area}_{2}=\left.k x\right|_{x_{2}} ^{x_{3}}-\frac{r^{2}}{2}\left[\arcsin \left(\frac{(x-h)}{r}\right)+\frac{\sin \left(2 \arcsin \left(\frac{(x-h)}{r}\right)\right)}{2}\right] \mid \begin{aligned} & x_{3} \\ & x_{2}\end{aligned}$

Plugging in the values we have:

$$
\text { Area }_{2} \approx 31.782 \mathrm{~m}^{2}
$$

Using y for $f_{3}(x)$ gives:

$$
\operatorname{Area}_{3}=\int_{x_{3}}^{x_{5}}\left[k+\sqrt{r^{2}-(x-h)^{2}}\right] d x
$$

Integrating equation (7) we obtain:

$$
\operatorname{Area}_{3}=\left.k x\right|_{x_{3}} ^{x_{5}}+\frac{r^{2}}{2}\left[\arcsin \left(\frac{(x-h)}{r}\right)+\frac{\sin \left(2 \arcsin \left(\frac{(x-h)}{r}\right)\right)}{2}\right] \mid \begin{aligned}
& x_{5} \\
& x_{3}
\end{aligned}
$$

Plugging in the values we get:

$$
\text { Area }_{3} \approx 46.128 \mathrm{~m}^{2}
$$

Finally, using y for $f_{4}(x)$ gives:

$$
\text { Area }_{4}=\int_{x_{1}}^{x_{4}} \sqrt{r^{2}-(x-h)^{2}} d x .
$$

Integrating equation (8) we have: 


$$
\operatorname{Area}_{4}=\frac{r^{2}}{2}\left[\arcsin \left(\frac{(x-h)}{r}\right)+\frac{\sin \left(2 \arcsin \left(\frac{(x-h)}{r}\right)\right)}{2}\right] \mid \begin{aligned}
& x_{4} \\
& x_{1}
\end{aligned}
$$

Plugging in the values (note that $k=0$ ) we obtain:

$$
\text { Area }_{4} \approx 23.363 \mathrm{~m}^{2}
$$

Plugging the equations (5), (6), (7), and (8) into equation (2) reveals that the floor area that will be cover with artificial grass is:

$$
\begin{gathered}
\begin{aligned}
\text { Area }(\text { artificial grass }) & =\text { Area }_{1}+\text { Area }_{2}+\text { Area }_{3}-\text { Area }_{4} \\
\text { Area }(\text { artificial grass })= & 120.749+31.782+46.128-23.363 \\
& \approx 175.3 \mathrm{~m}^{2} .
\end{aligned}
\end{gathered}
$$

As calculated previously, the entrance area that will be cover with wood is:

$$
\approx 23.4 \mathrm{~m}^{2} \text {. }
$$

\section{DISCUSSION}

The purpose of this experiment is to find accurate amount and cost of material needed to floor a rooftop. The goal is achieved. Integration helped find the exact area of the roof for the two main parts. The architect will need to buy $175.3 \mathrm{~m}^{2}$ of artificial grass to cover the planned grass floor of the roof. Another $23.4 \mathrm{~m}^{2}$ of wood is needed to cover the entrance of the roof. 
According to the Jordanian material market, $1 \mathrm{~m}^{2}$ of artificial grass costs 11.3 dollars and $1 \mathrm{~m}^{2}$ of Parquet wood costs 21.0 dollars (see Table 3). Therefore, the total cost will be 2472 US dollars $(175.3 \times 11.3+23.4 \times 21.0)$. The results are expected since adding the areas together will make a reasonable total area of a roof and the price is within the usual range. Using this technique in the field of design can help architects make their work environmentally efficient. Additionally, materials like artificial grass can be expensive, so this experiment can reduce of amounts paid in excess.

\section{CONCLUSION AND RECOMMENDATIONS}

The area of an irregularly shaped roof is found by building a relationship between different sections that the roof is divided into. Taking the integrals of those sections gives the calculations of the area of the two wanted parts. Suggestions regarding possible future projects revolving around the same issue include building a program that can scan irregular floors and give the needed areas. Another suggestion would be calculating the area of a room with more complicated irregular borders or objects in the middle. 
*All Measures are in meters

\begin{tabular}{|cc|}
\hline Symbols & definition \\
\hline $\boldsymbol{r}$ & Radius of a circle \\
\hline $\boldsymbol{c}$ & Center of a circle coordinates \\
\hline $\boldsymbol{k}$ & Horizontal length \\
\hline
\end{tabular}

\section{REFERENCES}

\section{Books:}

1. Stewart, J. (2016). Calculus: Early transcendentals. Boston, MA, USA: Cengage Learning.

2. Larson, Ron, and Bruce H. Edwards. Calculus of a Single Variable: Early Transcendental Functions. Cengage, 2019.

\section{Websites:}

1. Circle equation review | Analytic geometry (article). (n.d.). Retrieved December 07, 2020, from https://www.khanacademy.org/math/geometry/xff63fac4:hs-geo-conic-sections/hsgeo-circle-expanded-equation/a/circle-equation-review.

2. Libretexts. (2020, November 17). 1.1: Area Between Two Curves. Retrieved December 07, 2020 , from https://math.libretexts.org/Bookshelves/Calculus/Supplemental_Modules_(Calculus)/Integr al_Calculus/1: Area and Volume/1.1:_Area_Between_Two_Curves. 


\section{APPENDIX}

Table 1: table of points

\begin{tabular}{|cc|}
\hline Variable & Value (meter) \\
\hline $\boldsymbol{c}_{\mathbf{1}}$ & $(3.89,12.54)$ \\
\hline $\boldsymbol{c}_{\mathbf{2}}$ & $(8.63,14.7)$ \\
\hline $\boldsymbol{c}_{\mathbf{3}}$ & $(12.3,10.4)$ \\
\hline $\boldsymbol{c}_{\mathbf{4}}$ & $(0,2,0)$ \\
\hline $\boldsymbol{x}_{\mathbf{0}}$ & $(4.2,0.0)$ \\
\hline $\boldsymbol{x}_{\mathbf{1}}$ & $(7.35,0.0)$ \\
\hline $\boldsymbol{x}_{\mathbf{2}}$ & $(10.22,0.0)$ \\
\hline $\boldsymbol{x}_{\mathbf{3}}$ & $(11.9,0.0)$ \\
\hline $\boldsymbol{x}_{\mathbf{4}}$ & $(13.8,0.0)$ \\
\hline $\boldsymbol{x}_{\mathbf{5}}$ & \\
\hline & \\
\hline
\end{tabular}

Table 2: table of radii

\begin{tabular}{|cc|}
\hline Variable & Value (meter) \\
\hline $\boldsymbol{r}_{\mathbf{1}}$ & 4.47 \\
\hline $\boldsymbol{r}_{\mathbf{2}}$ & 1.71 \\
\hline $\boldsymbol{r}_{\mathbf{3}}$ & 2.72 \\
\hline $\boldsymbol{r}_{\mathbf{4}}$ & 3.87 \\
\hline
\end{tabular}


Table 3: Material prices in Amman, Jordan

\begin{tabular}{|cc|}
\hline Material & Price $\left(\right.$ per $\left.\mathbf{m}^{\mathbf{2}}\right)$ \\
\hline Artificial grass of $15 \mathrm{~mm}$ thickness & $\$ 11.3$ \\
\hline Parquet wooden flooring of $11 \mathrm{~mm}$ thickness & $\$ 21.0$ \\
\hline
\end{tabular}

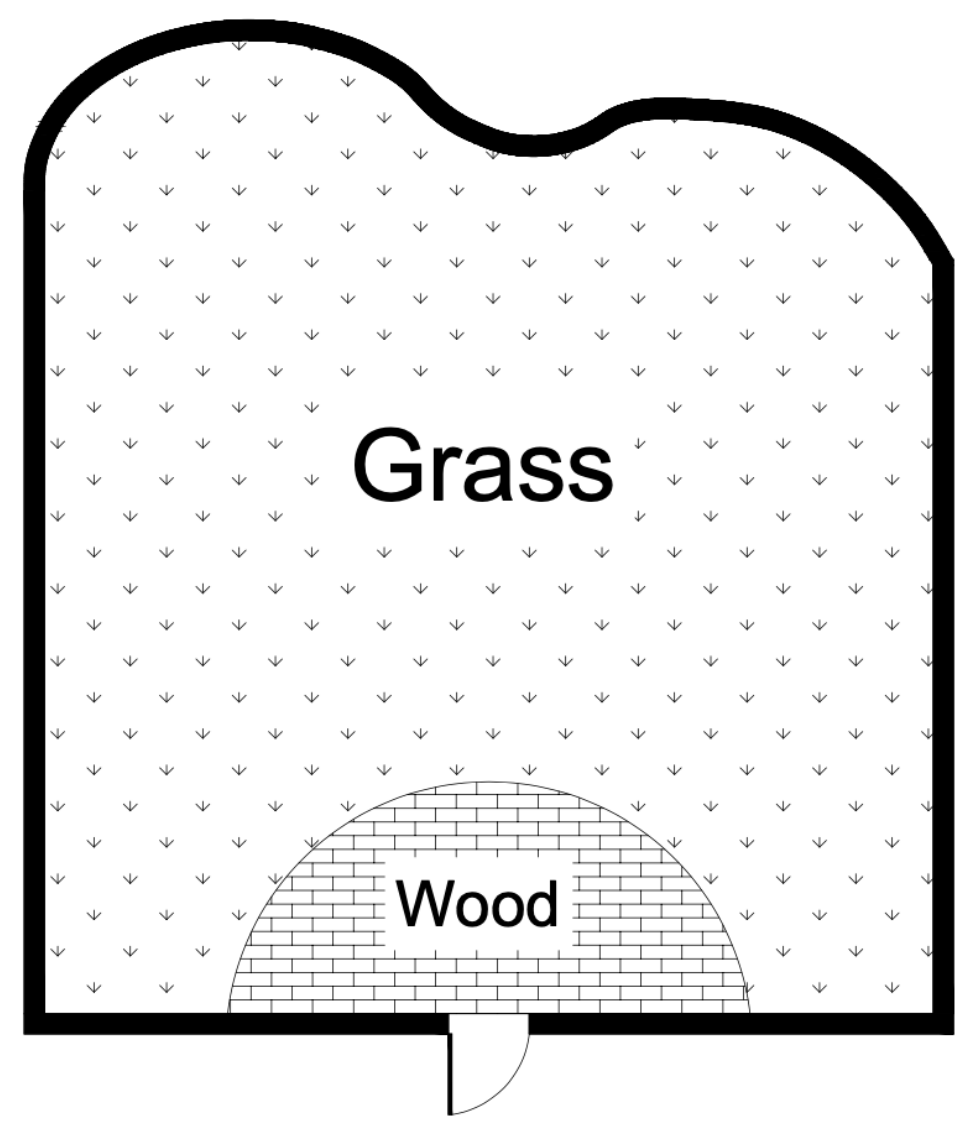

\section{Entrance}

Figure 3: plan model of the roof garden 